\title{
Cognitive-Enhancing Effect of a Hydroethanolic Extract of Crinum macowanii against Memory Impairment Induced by Aluminum Chloride in BALB/c Mice
}

\author{
Mohammed S. Jilani (D), ${ }^{1}$ Dexter Tagwireyi ${ }^{D},{ }^{1}$ Louis L. Gadaga $\left(\mathbb{D},{ }^{1}\right.$ Charles C. Maponga $\left(\mathbb{D},{ }^{2}\right.$ \\ and Cosmas Mutsimhu (iD ${ }^{1}$ \\ ${ }^{1}$ Drug and Toxicology Information Service (DaTIS), School of Pharmacy and Department of Clinical Pharmacology, College of \\ Health Sciences, University of Zimbabwe, P.O. Box A 178, Avondale, Harare, Zimbabwe \\ ${ }^{2}$ School of Pharmacy, University of Zimbabwe, P.O. Box MP167, Mount Pleasant, Harare, Zimbabwe \\ Correspondence should be addressed to Mohammed S. Jilani; saaqibj@gmail.com
}

Received 23 January 2018; Revised 16 August 2018; Accepted 27 August 2018; Published 4 October 2018

Academic Editor: Antonio Orlacchio

Copyright (c) 2018 Mohammed S. Jilani et al. This is an open access article distributed under the Creative Commons Attribution License, which permits unrestricted use, distribution, and reproduction in any medium, provided the original work is properly cited.

\begin{abstract}
Crinum macowanii is a bulbous plant indigenous to many parts of Southern Africa. Extracts of C. macowanii have gained interest since the discovery of various alkaloids, few of which possess acetylcholinesterase inhibitory activity. The present study was performed to evaluate the effect of a crude hydroethanolic extract of $C$. macowanii against aluminum chloride-induced memory impairment in mice using the Morris water maze and the novel object recognition task. C. macowanii $(10,20$, and $40 \mathrm{mg} / \mathrm{kg}$ p.o) was administered daily for five weeks, while donepezil $(3 \mathrm{mg} / \mathrm{kg}$ p.o) was used as the positive control. C. macowanii at a dosage of $40 \mathrm{mg} / \mathrm{kg}$ showed a significantly lower escape latency than the negative control $(P<0.0001)$ and was found to be comparable to donepezil $3 \mathrm{mg} / \mathrm{kg}$ in the Morris water maze test. C. macowanii at $40 \mathrm{mg} / \mathrm{kg}$ exhibited a significantly higher discrimination index than aluminum chloride-treated mice in the novel object recognition task. The results may support the usefulness of C. macowanii in the management of dementia and related illnesses.
\end{abstract}

\section{Introduction}

Alzheimer's disease (AD) is a chronic neurodegenerative disease characterized by cognitive dysfunction, psychiatric, and behavioral disturbances [1]. Hallmark pathological characteristics of $\mathrm{AD}$ include the deposition of amyloid- $\beta(\mathrm{A} \beta)$ plaques and neurofibrillary tangles in the brain accompanied by synaptic dysfunction [2]. This is the amyloid hypothesis, which postulates that amyloid deposits in the brain are the main cause of $\mathrm{AD}$ [3], while the Tau hypothesis suggests that abnormalities in the hyperphosphorylated tau protein are the cause of AD [4]. Early-onset familial Alzheimer's disease is an uncommon form of $\mathrm{AD}$ caused by a mutation in one of at least three genes: PSEN1, APP gene, and PSEN2 [5]. Oxidative stress also appears to be a major cause of $\mathrm{AD}$-related pathologies caused by oxidative reactive species [5]. AD is incurable, and presently, there is no treatment that can retard the progression of the disease [6]. The cholinergic hypothesis concludes that the loss of cholinergic function results in memory loss and disruption of cognitive function $[7,8]$.

Current treatment of $\mathrm{AD}$ revolves around the increase in cholinergic transmission between the synaptic cleft by the use of acetylcholinesterase inhibitors (AChEi). These drugs include galantamine, rivastigmine, and donepezil [9]. These medications do not slow the progression of the disease; however, they do provide a modest but consistent improvement in functional and cognitive ability [10]. Since rivastigmine and galantamine are both related to natural products [11], there may still be a benefit in investigating more naturally occurring compounds in order to discover other and perhaps more effective AChEi.

The Amaryllidaceae family contains 1310 species which are widely distributed, and Crinum is an important genus of this family [12]. Over the years, alkaloids have been identified 
as the main active constituents of interest in Crinum species. These include lycorine-, crinine-, belladine-, galanthamine-, lycorinine-, and tazettine-type alkaloids [12-14].

Crinum macowanii (CM), a member of the Crinum genus, is known as umduze or dururu in the southern African languages of isiNdebele and Shona, respectively, and has a variety of medicinal uses [15]. Various alkaloids which have been isolated from CM include lycorine, 1-O-acetyllycorine, crinine, powelline, crinamine, crinamidine, 3-O-acetylhamayne, 1-epideacetylbowdensine, and cherylline [16]. Some of these alkaloids such as lycorine have been reported to possess acetylcholinesterase (AChE) inhibitory activity [17] and hence could be of benefit in treating dementia. In fact, a recent study reported that a crude hydroethanolic extract of $\mathrm{CM}$ had nootropic-like activity in a scopolamine-induced amnesia BALB/c mouse model [18]. However, while the scopolamine $\mathrm{AD}$ mouse model used in the aforementioned study [18] is commonly used for assessing nootropic-like activity in rodents, it only assesses cognitive enhancement resulting from the increase in the neurotransmitter-acetylcholine. Yet evidence in the literature suggests that AD is primarily caused by neurodegeneration. Thus, it is possible that the results seen in the study could not be replicated in a model which exhibits neurodegeneration. There is, therefore, a need to validate the results seen by Mugwagwa and colleagues [18] in a model that may be closer to AD. Hence, in this study, we have investigated the possible nootropic effects of CM using the aluminum chloride-induced dementia mouse model. This model not only causes learning memory impairment and cognitive decline in mice but also results in neurodegeneration [19-21].

In order to investigate these effects, the Morris water maze (MWM) and novel object recognition (NOR) test protocols were used. In addition to the behavioral tests, we also investigated the AChE inhibitory and free radical scavenging activity.

\section{Materials and Methods}

2.1. Plant Collection. Fresh bulbs of C. macowanii were collected in November 2014 at the University of Zimbabwe (UZ) grounds, Harare coordinates $17^{\circ} 47^{\prime} 14.5^{\prime \prime} \mathrm{S} 31^{\circ} 03^{\prime} 06.4^{\prime \prime}$ E. The plant sample was authenticated by a taxonomist from the Botanical Gardens and National Herbarium in Harare. A total number of 24 bulbs were collected for this study.

2.2. Preparation of Crude Extract. The crude extract was prepared as described by Mugwagwa et al. [18]. Briefly, fresh bulbs of $C$. macowanii were washed with water and peeled. They were dried under a shade for a period of 3 weeks. To ensure complete drying, the scales were further oven-dried at 55 degrees Celsius. The dried scales were reduced to fine powder using a Thomas Scientific Mill Model 4 (ThomasWiley Laboratory, USA) with a sieve size of $1 \mathrm{~mm}$. A total of $1.1 \mathrm{~kg}$ of dried powder was obtained. The powder was then macerated in aqueous ethanol $(70 \% v / v$, up to $8 \mathrm{~L})(1: 10$ $w / v)$. To ensure the extraction of alkaloids, the maceration was continued for 72 hours with occasional shaking at room temperature. The mixture was then filtered to remove the bulky material using a mutton cloth. The finer material was filtered out by the process of vacuum filtration using Merck number 454 filter paper. This solution was concentrated using a Heidolph instrument, which was the Rotavapor 4000 (Heidolph, Germany). The resultant paste was freezedried using Heto Lab Equipment, Heto Freeze Dryer 3 (Heto-Holten A/S, Denmark), for 48 hours to obtain $102 \mathrm{~g}$ of the powdered crude extract. This powder was stored in a cool dark place in a desiccator.

2.3. Animals. Male BALB/c mice (22-37g) were purchased from the animal house at the University of Zimbabwe. The mice were housed at the animal holding room in the Clinical Pharmacology Department of the University of Zimbabwe and were allowed to acclimatize for a period of one week. A natural hour light/dark cycle at room temperature was maintained, while a standard pellet diet was made freely accessible. Tap water was provided ad libitum. Authorization to use laboratory animals for the research project was granted by the Joint Research and Ethical Committee (JREC approval number: JREC/121/15).

2.4. Drugs and Reagents. Donepezil hydrochloride (DONZ) (Actavis Limited, India) and crude extract of C. macowanii were used. Aluminum chloride (ALCL) was obtained from the School of Pharmacy, University of Zimbabwe. Normal saline was used as the vehicle for both the CM and the DONZ. Acetylcholinesterase enzyme assay kit was purchased from Sigma Aldrich, South Africa. DPPH (2,2-Diphenyl-1(2,4,6-trinitrophenyl)hydrazyl) and ascorbic acid were obtained from the Biochemistry Department, University of Zimbabwe. The study was partly funded by the researcher and the School of Pharmacy, University of Zimbabwe.

2.5. Grouping and Treatment Schedule. Mice were randomly put into six different groups. Tails of each mouse were marked with a nontoxic marker.

The mice were divided into 6 groups with 6 mice in each group. The experimental design was conducted as described by Mugwagwa et al. [18] and Linardaki et al. [22]. The experimental design was as follows:

Group 1: CM $10 \mathrm{mg} / \mathrm{kg} /$ day, p.o. + ALCL $50 \mathrm{mg} / \mathrm{kg} /$ day p.o. for 5 weeks

Group 2: CM $20 \mathrm{mg} / \mathrm{kg} /$ day, p.o. + ALCL $50 \mathrm{mg} / \mathrm{kg} /$ day p.o. for 5 weeks

Group 3: CM $40 \mathrm{mg} / \mathrm{kg} /$ day, p.o. + ALCL $50 \mathrm{mg} / \mathrm{kg} /$ day p.o. for 5 weeks

Group 4: DONZ 3 mg/kg/day, p.o. + ALCL 50 mg/kg/day p.o. for 5 weeks (positive control)

Group 5: water p.o. (vehicle control); for 5 weeks

Group 6: ALCL $50 \mathrm{mg} / \mathrm{kg} /$ day p.o. (negative control) 5 weeks

ALCL was given 30 minutes before DONZ and CM extract to avoid possible interactions between aluminum and other substances.

After 5 weeks, the mice were subjected to the MWM and the NOR test. Following the behavioral tests, the acetylcholinesterase enzyme test and the DPPH free radical scavenging 
test were performed. In addition, FT-IR and LC-MS fingerprinting analysis of the same extract were also conducted.

\subsection{Behavioral Tests}

2.6.1. Morris Water Maze Test (MWM). The water maze used was a large metallic circular pool painted black on the inside ( $110 \mathrm{~cm}$ diameter and $40 \mathrm{~cm}$ in height). Water $\left(20 \pm 1^{\circ} \mathrm{C}\right)$ was filled to a depth of $30 \mathrm{~cm}$. The water maze area was divided into four equal quadrants, and a colorless escape circular platform $(10 \mathrm{~cm}$ in diameter and $25 \mathrm{~cm}$ in height) was located in the south-west quadrant. The experiment was monitored using a camera which was positioned directly above the pool. The MWM task was performed as described by BromleyBrits et al. [23]. Briefly, the experiment was conducted over a period of 6 days. Each mouse was gripped at the base of the tail and gently placed in the water, and time was noted for the mouse to find the platform (escape latency). Mice were given 4 trials per day. On day 1, the platform was made visible by the water being $1 \mathrm{~cm}$ below the platform. On days $2-5$, the platform was submerged below the water. Day 6 was the probe trial in which the platform was completely removed, and the amount of time spent by the mouse in the target quadrant (south-west) was noted. Each animal was allowed 90 seconds to locate the platform. If an animal failed to locate the platform within this period, it was gently guided to the platform. The animal was left on the platform for $5 \mathrm{~s}$ upon locating it. The mouse was then dried with a towel and placed back in the cage.

2.6.2. Novel Object Recognition (NOR) Task. The NOR task was conducted as described by Mugwagwa et al. [18] to assess short-term and long-term memory. The apparatus consisted of an open rectangular box made of plastic with the following dimensions: $43 \mathrm{~cm} \times 31 \mathrm{~cm} \times 16 \mathrm{~cm}$. The experiment was monitored by a camera placed directly above the arena. The test consisted broadly of 2 phases: a sample and test phase. During the sample phase, 2 identical objects (white, square container) were placed equidistant from each other. The mouse was placed in the arena for 5 minutes and then placed back in the cage. The process was repeated for all the animals. The apparatus was cleaned with ethanol between each trial interval so as to remove any olfactory clues which could have been left behind during previous trials. The position of the identical and novel objects was interchanged from left to right in order to prevent bias for a particular location. The same procedure was conducted for the test phase; however, one object was replaced by a novel object (green plastic toy bus). After 5 days, the same procedure was repeated except that the test phase was conducted $24 \mathrm{hrs}$ after the sample phase. The time taken to explore an object was noted.

Object exploration was defined as the mouse licking, sniffing, touching the objects with the paws, or if its head was oriented towards the object within a distance of $2 \mathrm{~cm}$.

The following parameters were measured: time (in seconds) spent exploring familiar object $\left(T_{\mathrm{f}}\right)$, time (in seconds) spent exploring the novel object $\left(T_{\mathrm{n}}\right)$, and total time (in seconds) spent exploring both objects $\left(T_{\mathrm{f}}+T_{\mathrm{n}}\right)$. The percentage of discrimination index (DI\%) was determined using the following equation:

$$
\mathrm{DI}(\%)=\left(\frac{T_{\mathrm{n}}}{T_{\mathrm{n}}+T_{\mathrm{f}}}\right) \times 100
$$

where $\mathrm{DI}=$ discrimination index, $T_{\mathrm{n}}=$ time (in seconds) spent exploring the novel object, and $T_{\mathrm{f}}=$ time (in seconds) spent exploring the familiar object.

\subsection{Biochemical Tests}

2.7.1. Acetylcholinesterase Enzyme Activity Test. Three mice from each study group were sacrificed, and their brains were isolated. The acetylcholinesterase enzyme (AChE) activity test was performed using the AChE enzyme kit from Sigma Aldrich, which measures the AChE activity of the brain homogenate. The assay is based on the Ellman method in which thiocholine, produced by $\mathrm{AChE}$, reacts with 5,5\$dithiobis (2-nitrobenzoic acid) to form a colorimetric $(412 \mathrm{~nm})$ product, which is proportional to the AChE activity present. The isolated brain samples were homogenized with $0.1 \mathrm{M}$ phosphate buffer, $\mathrm{pH} 7.5$, followed by centrifugation at $14,000 \mathrm{rpm}$. The supernatant was used for the assay. The following equation was used to calculate the ACHE activity:

$$
\operatorname{AChE} \operatorname{activity}(\text { units } / \mathrm{L})=\frac{A_{2 \text { min }}-A_{10 \mathrm{~min}}}{A_{\text {calib }}-A_{\text {blank }}} \times n \times 200 \text {, }
$$

where $200=$ equivalent activity (units/L) of the calibrator when assayed-read at 2 minutes and 10 minutes, $n=$ dilution factor, $A_{2 \min }=$ absorbance of the calibrator at 2 minutes, $A_{10 \text { min }}=$ absorbance of the calibrator at 10 minutes, $A_{\text {cali- }}$ brator=absorbance of the calibrator at 10 minutes, and $A_{\text {blank }}=$ absorbance of the blank at 10 minutes.

2.7.2. DPPH Radical Scavenging Assay. The free radical scavenging effect of CM was examined using the method employed by Doreddula et al. [24]. Briefly, one $\mathrm{mL}$ of $0.2 \mathrm{mM} \mathrm{DPPH}$ solution in methanol was mixed with the $1 \mathrm{~mL}$ extracts of $3.2,6.3,12.5,25,50,100,200$, and $400 \mu \mathrm{g} / \mathrm{mL}$ concentrations, respectively. Absorbance was measured at $517 \mathrm{~nm}$ after incubation of the mixture in the dark for $20 \mathrm{~min}$. The free radical scavenging activity of $\mathrm{CM}$ was determined by comparing its absorbance with that of a blank solution. Ascorbic acid was used as a reference standard.

The ability to scavenge the DPPH radical was calculated using the following equation:

$$
\mathrm{DPPH} \text { radical scavenging activity }(\%)=\frac{A_{b}-A_{s}}{A_{b}} \times 100 \text {, }
$$

where $A_{\mathrm{b}}=$ absorbance of the blank and $A_{\mathrm{s}}=$ absorbance of the sample.

2.8. Fingerprinting of the Extract of Crinum macowanii. Phytochemical fingerprinting of the extract used in this study was done using LC-MS and FT-IR analysis. In addition, rudimentary qualitative phytochemical screening was conducted to identify possible secondary metabolites in the extract. 
2.8.1. LC-MS Analysis. LC-MS analysis was carried out using an Agilent HPLC 1260 System, and an Agilent QTOF 6530 mass spectrometer was used as the detector for fingerprinting the extract. $1 \mathrm{mg}$ of free dried sample extract was dissolved in $1 \mathrm{~mL}$ of methanol:water $(50: 50)$ by volume. The resulting mixture was transferred into a $5 \mathrm{~mL}$ syringe and filtered through a $0.22 \mu \mathrm{m}$ acrosdisc syringe filter into an HPLC vial for LC-MS/MS analysis. Gradient elution with composition as follows: solvent A: (water with $0.1 \%$ formic acid), solvent B: acetonitrile with $0.1 \%$ formic acid, and injection volume: $5 \mu \mathrm{L}$. Column temperature was maintained at $40^{\circ} \mathrm{C}$ and with a total run time of 27 minutes. The LC-Q-TOF-MS data was analyzed using Agilent Technologies Mass Hunter Software Version B.07.03 (509).

2.8.2. FT-IR Analysis. A Fourier-transform infrared (FT-IR) spectrophotometer was used to identify the characteristic functional groups in the extract as a further fingerprint. A portion of the freeze-dried sample was placed on the FT-IR plate with a spatula, and the spectrum was read after background subtraction using the Perkin Elmer Analyst software version 10.5.2.

2.8.3. Phytochemical Screening. Rudimentary phytochemical screening was performed as described by Yadav et al. 2014 [25]. Phytochemical tests were performed for tannins, flavonoids, alkaloids, steroids, glycosides, and saponins.

(a) Alkaloids: test for alkaloids. The crude extract was mixed with $2 \mathrm{~mL}$ of $1 \% \mathrm{HCl}$ and heated gently. Mayer's and Wagner's reagents were then added to the mixture. The turbidity of the resulting precipitate was taken as evidence for the presence of alkaloids

(b) Steroids: test for steroid. The crude extract was mixed with $2 \mathrm{~mL}$ of chloroform and concentrated sulfuric acid was added sidewise. A red color produced in the lower chloroform layer indicated the presence of steroids

(c) Glycosides: test for glycosides Liebermann's test. The crude extract was mixed with each of $2 \mathrm{~mL}$ of chloroform and $2 \mathrm{~mL}$ of acetic acid. The mixture was cooled in ice. Carefully concentrated sulfuric acid was added. A color change from violet to blue to green indicated the presence of a steroidal nucleus, i.e., glycone portion of a glycoside

(d) Saponins: test for saponins. The crude extract was mixed with $5 \mathrm{~mL}$ of distilled water in a test tube, and it was shaken vigorously. The formation of stable foam was taken as an indication for the presence of saponins

(e) Flavonoids: alkaline reagent test. The crude extract was mixed with $2 \mathrm{~mL}$ of $2 \%$ solution of $\mathrm{NaOH}$. An intense yellow color was formed which turned colorless on the addition of a few drops of diluted acid which indicated the presence of flavonoids

\section{Data Analysis}

All the results were expressed as mean \pm SEM. Data for the MWM test were analyzed by analysis of variance (ANOVA) followed by Tukey's post hoc test in GraphPad Instat package version 7.03. Data analysis for the NOR task was evaluated using one-way analysis of variance (ANOVA) followed by Dunnett's Multiple Comparison tests in GraphPad Prism (version 7.03).

Two-way repeated measures (mixed model) ANOVA followed by Bonferroni posttests were used to compare the two objects in the object recognition task in GraphPad Prism (version 7.03). Data for the biochemical tests were analyzed using two-way analysis of variance (ANOVA) followed by post hoc multiple comparisons using Bonferroni tests. $P<0.05$ was considered significant.

\section{Results}

4.1. Morris Water Maze. The effect of Crinum macowanii at three doses $(10,20$, and $40 \mathrm{mg} / \mathrm{kg})$ on aluminum chlorideinduced memory impairment was investigated. The MWM behavioral test was utilized to assess the escape latencies (EL) and time spent in the target quadrant (TSTQ) expressed in seconds.

Results for the EL for all groups are shown in Figure 1(a). There were significant differences in the EL amongst the groups during the course of 5 days $(f=37.43$, $P<0.0001)$. There was also a significant difference in the EL between mice in the CM $40 \mathrm{mg} / \mathrm{kg}$ group and Aluminum chloride (ALCL) group $(P<0.0001)$ with a mean EL of $26.77 \pm 1.67 \mathrm{~s}$ and $56.43 \pm 2.84 \mathrm{~s}$, respectively. A significant difference was also noted between the DONZ $3 \mathrm{mg} / \mathrm{kg}$ group and ALCL group $(P<0.0001)$. No significant difference in EL was seen between CM group at $40 \mathrm{mg} / \mathrm{kg}$ and DONZ $3 \mathrm{mg} / \mathrm{kg}$ group $(P<0.9070)$. The EL for the ALCL group (mean of $56.43 \pm 2.84 \mathrm{~s}$ ) was significantly higher than the vehicle control group (water, mean of $40.53 \pm 2.3 \mathrm{~s}$ ). The DONZ $3 \mathrm{mg} / \mathrm{kg}$ group demonstrated the lowest EL $(23.54 \pm 1.64 \mathrm{~s})$ followed by the $\mathrm{CM}$ at $40 \mathrm{mg} / \mathrm{kg}$ group $(26.77 \pm 1.67 \mathrm{~s})$. Comparing the three dosage groups of $\mathrm{CM}$, the $\mathrm{CM}$ at $40 \mathrm{mg} / \mathrm{kg}$ group showed the lowest EL followed by the $\mathrm{CM}$ at 20 and $10 \mathrm{mg} / \mathrm{kg}$ groups.

On day 6 , the probe trial was performed wherein the time each mouse spent in the target quadrant (TSTQ) was noted. Results are shown in Figure 1(b). The ALCL group spent the least amount of time in the target quadrant $(4.5 \pm 1.2 \mathrm{~s})$, while the highest was seen with the DONZ $3 \mathrm{mg} / \mathrm{kg}$ group $(28.83 \pm 2.13 \mathrm{~s})$. No significant difference was seen in the time spent in the target quadrant between DONZ $3 \mathrm{mg} / \mathrm{kg}$ and CM $40 \mathrm{mg} / \mathrm{kg}(P=0.9358)$. The CM $40 \mathrm{mg} / \mathrm{kg}$ treated group showed significantly more time spent in the target quadrant than the ALCL-treated group $(P<0.0001)$.

4.2. Novel Object Recognition Test. The NOR test assessed short-term and long-term memory function. It consisted of a sample and test phase. The discrimination index (DI) was calculated for each trial of the test phase to assess the preference for the novel object. 
Escape latencies

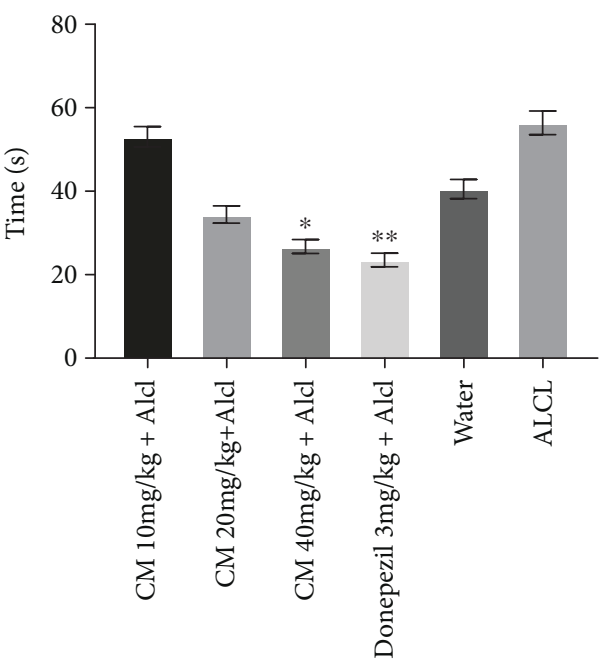

(a)
Time spent in target quadrant

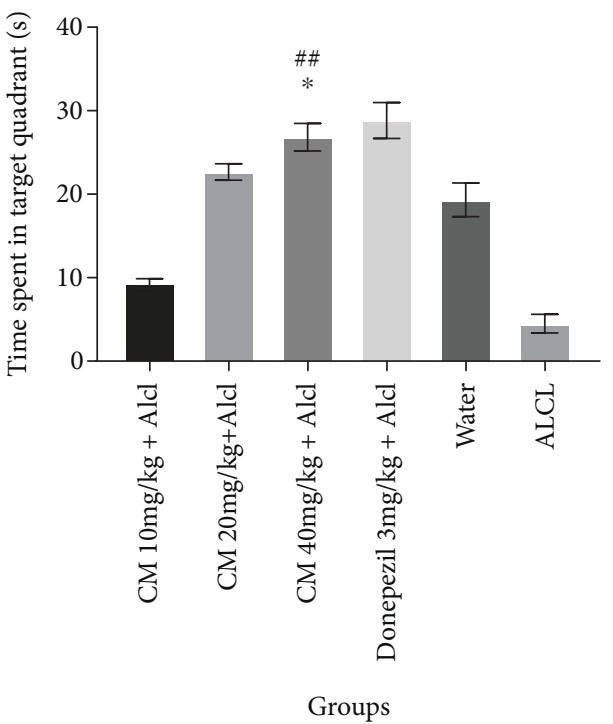

(b)

Figure 1: (a) Escape latencies (s) for all groups from day 1 to day 5. Effect of Crinum macowanii (10, 20, and $40 \mathrm{mg} / \mathrm{kg}$ ) on Morris water maze task. *versus ALCL, $P<0.0001$, ${ }^{* *}$ versus ALCL, $P<0.0001$. One-way analysis of variance followed by Tukey's post hoc test. (b) Time (s) spent in the target quadrant. * versus donepezil, $P=0.9538,{ }^{\# \#}$ versus ALCL-treated group, $P<0.0001$.

The DI for the short-term phase is shown in Figure 2(c). During the short-term phase, there was no significant difference in the DI amongst the groups except between the CM $40 \mathrm{mg} / \mathrm{kg}$ and ALCL groups $(P<0.0316)$. The DI for the $\mathrm{CM} 40 \mathrm{mg} / \mathrm{kg}$ group $(\% \mathrm{DI}=58.97 \pm 1.05)$ was higher than the DONZ $3 \mathrm{mg} / \mathrm{kg}$ group ( $\% \mathrm{DI}=53.62 \pm 2.1$ ) during the short-term memory task, although this was not significant $(P=0.4509)$. During the short-term memory test, the DI was above $50 \%$ for all groups except for the ALCL-treated group (\% DI $=49.1 \pm 3.55)$. The same was observed for the long-term memory test ( $\% \mathrm{DI}=46.58 \pm 3.76)$.

During the long-term memory test shown in Figure 2(f) the DONZ $3 \mathrm{mg} / \mathrm{kg}$ treated group showed a significantly higher DI than the ALCL group $(P<0.0071)$.

During the sample phase of the short-term memory test, there was no significant difference in the time spent exploring each identical object $(P>0.05)$. In the test phase of the shortterm memory test, CM $40 \mathrm{mg} / \mathrm{kg}$ treated mice spent significantly more time exploring the novel object than the familiar object $(P=0.0180)$.

During the sample phase of the long-term memory test, there was no significant difference in the time spent exploring each identical object $(P>0.05)$. The CM 10, 20, and $40 \mathrm{mg} / \mathrm{kg}$, DONZ $3 \mathrm{mg} / \mathrm{kg}$, and the control (water) treated mice spent more time exploring the novel object; however, this difference was not significant. In both test phases for short and long-term memory, the ALCL-treated mice showed more time exploring the familiar object than the novel object. This again was not statistically significant.

4.3. Acetylcholinesterase Enzyme Activity Test. The results for the AChE test are shown in Figure 3. The CM-treated group at $40 \mathrm{mg} / \mathrm{kg}$ exhibited significantly decreased acetylcholinesterase enzyme (AChE) activity as compared to the
ALCL-treated group $(P<0.0001)$ and the control group $(P=0.0013)$. The donepezil-treated group showed the lowest AChE activity $(1421 \pm 23.75 \mathrm{UL})$ followed by the CM $40 \mathrm{mg} / \mathrm{kg}$ treated group $(2549 \pm 28.65 \mathrm{UL})$. The donepeziltreated group was seen to have a significantly lower AChE activity than the ALCL-treated group $(P<0.0001)$.

4.4. DPPH Radical Scavenging Assay. DPPH radical scavenging activity is shown in Figure 4. A dose-dependent increase in free radical scavenging activity was seen with an increased dose of CM; however, the DPPH free radical scavenging activity of ascorbic acid was significantly higher $(P<0.0001)$ than that of $\mathrm{CM}$ at all concentrations.

\subsection{Results for Fingerprinting}

4.5.1. LC-MS Analysis. The results for LC-MS chemical fingerprint are presented in Figure 5. The extract used in this study showed a number of prominent links. As this was meant to only be a fingerprint, no attempt was made at trying to identify the compounds associated with the respective retention times and mass to charge ratios.

4.5.2. FT-IR Analysis. The FT-IR fingerprint of the compound suggested the presence of various functional groups, which included alkyl, ketone, aldehyde, carboxylic acids, esters, and amide groups. This is presented in Figure 6.

4.5.3. Phytochemical Screening. Rudimentary phytochemical screening of the crude hydroethanolic extract of $\mathrm{CM}$ suggested the presence of alkaloids, steroids, glycosides, saponins, and flavonoids. 


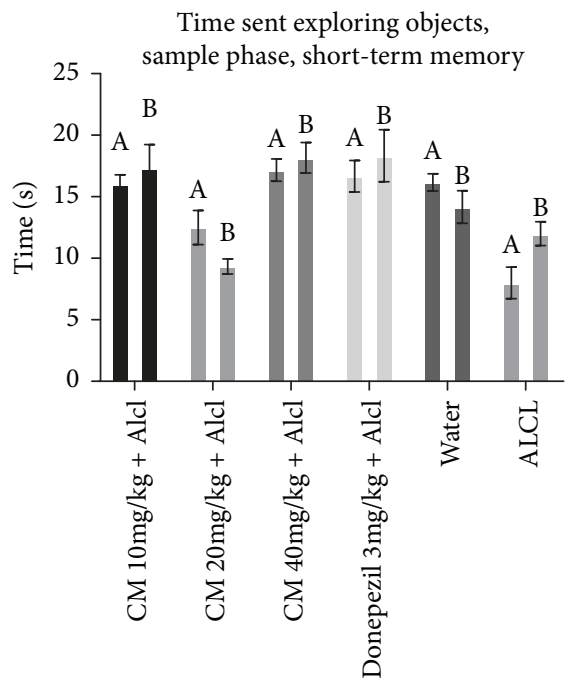

$\mathrm{A}=$ familiar object $\mathrm{B}=$ novel object

(a)

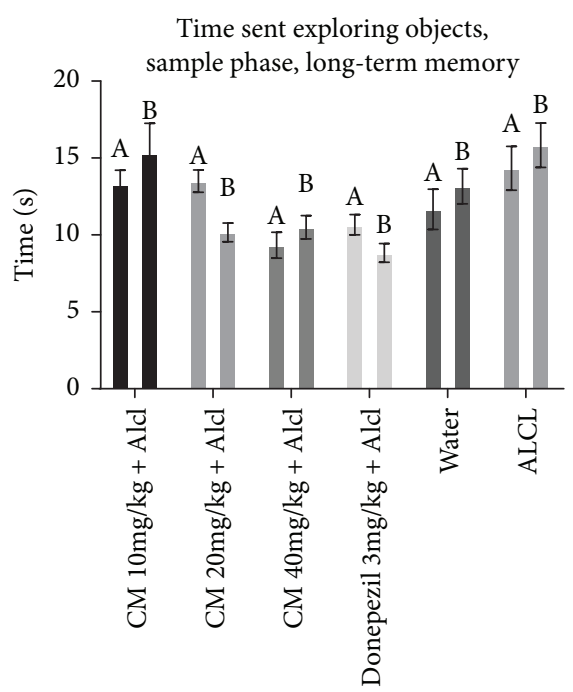

$\mathrm{A}=$ familiar object $\mathrm{B}=$ novel object

(d)

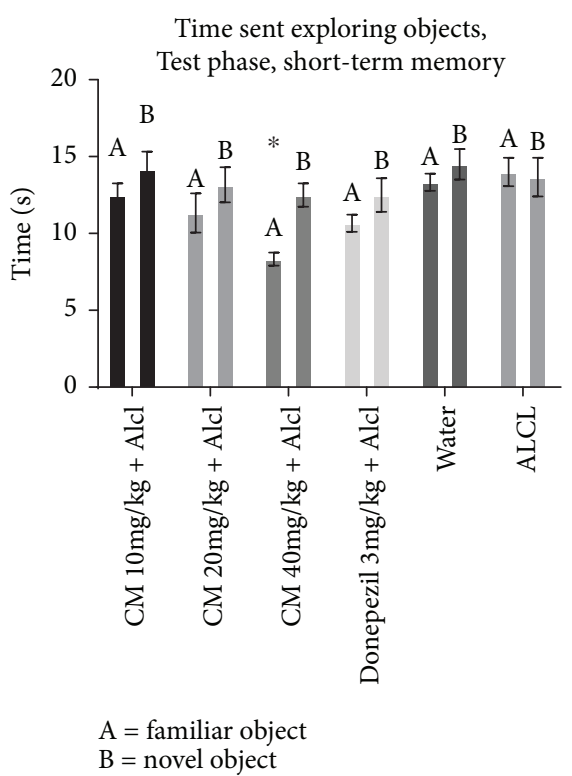

(b)

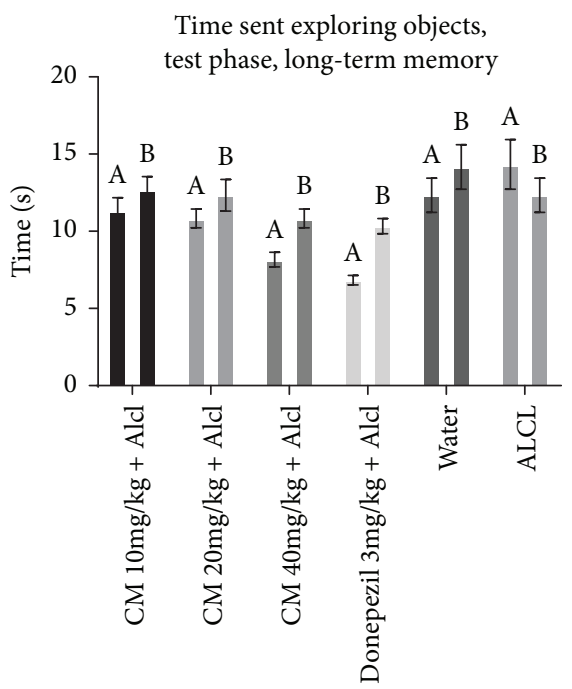

$A=$ familiar object $\mathrm{B}=$ novel object

(e)

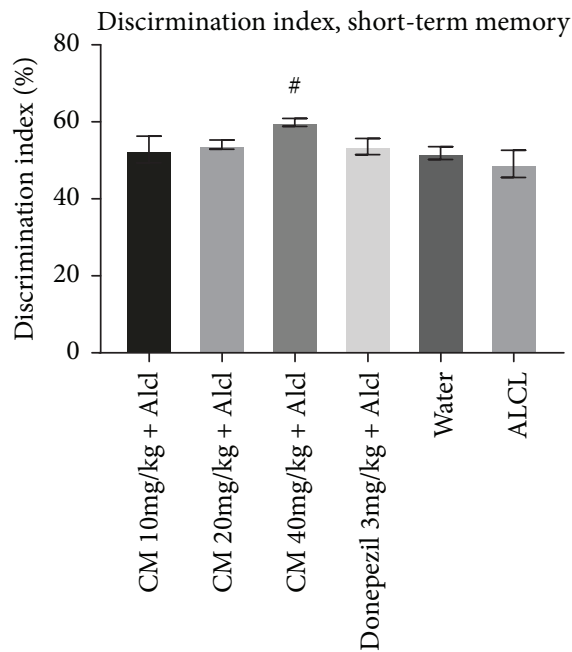

(c)

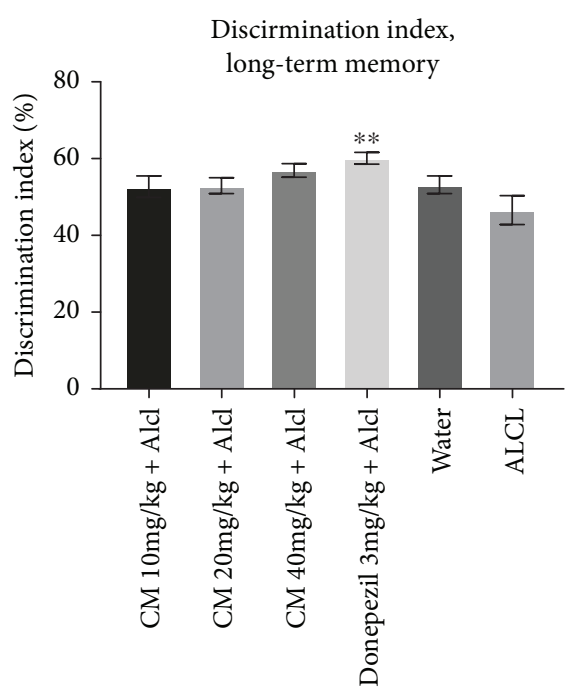

(f)

FIGURE 2: (a) Novel object recognition test, short-term memory, and sample phase. (b) Novel object recognition test, test phase, and shortterm memory. (c) Novel object recognition test, discrimination index for short-term memory. Effect of Crinum macowanii (CM) (10, 20, and $40 \mathrm{mg} / \mathrm{kg}$ ) on the short-term memory object recognition task: (a) exploration times in the sample phase, (b) exploration times in the test phase, and (c) discrimination index. ${ }^{*} P=0.0180$ novel object versus familiar object, ${ }^{*} P=0.0358$ versus ALCL. ((a) and (b)) Two-way repeated measures (mixed model) ANOVA followed by Bonferroni posttests. (c) One-way analysis of variance followed by Dunnett's Multiple Comparison tests. (d) Novel object recognition test, sample phase, and long-term memory. (e) Novel object recognition test, test phase, and long-term memory. (f) Novel object recognition test, discrimination index, and long-term memory. Effect of Crinum macowanii (CM) $(10,20$, and $40 \mathrm{mg} / \mathrm{kg}$ ) on the long-term memory object recognition task: (d) exploration times in the sample phase, (e) exploration times in the test phase, and (f) discrimination index. $\left({ }^{* *} P=0.0071\right.$ versus ALCL). ((d) and (e)) Two-way repeated measures (mixed model) ANOVA followed by Bonferroni posttests. (f) One-way analysis of variance followed by Dunnett's Multiple Comparison tests.

\section{Discussion}

The current study investigated the effect of a hydroethanolic extract of Crinum macowanii bulbs in the aluminum mouse model for Alzheimer's disease using the novel object recognition task and the Morris water maze test for assessing memory function.

Memory function in animal models is generally assessed using various behavioral tasks. We have employed the Morris water maze and novel object recognition task. The MWM 


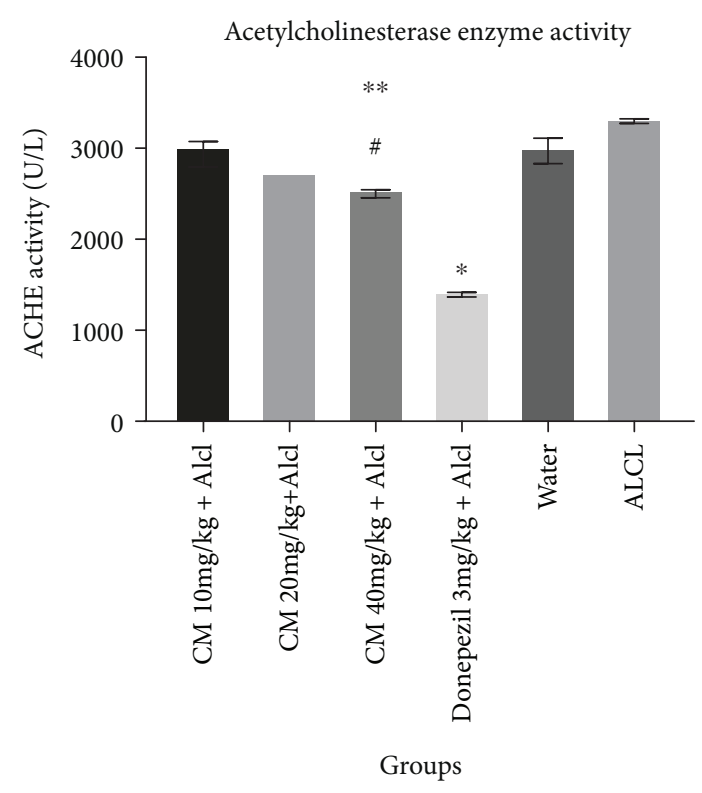

FIgURe 3: Acetylcholinesterase enzyme activity assay. Effect of $C$. macowanii on AChE activity in the brain homogenate of mice. Values are mean \pm SEM. Data was analyzed by two-way ANOVA followed by Bonferroni multiple comparisons test. ${ }^{*} P<0.0001$ versus the control group; ${ }^{\#} P=0.0013$ versus the control group; ${ }^{* *} P<0.001$ versus the ALCL-treated group.

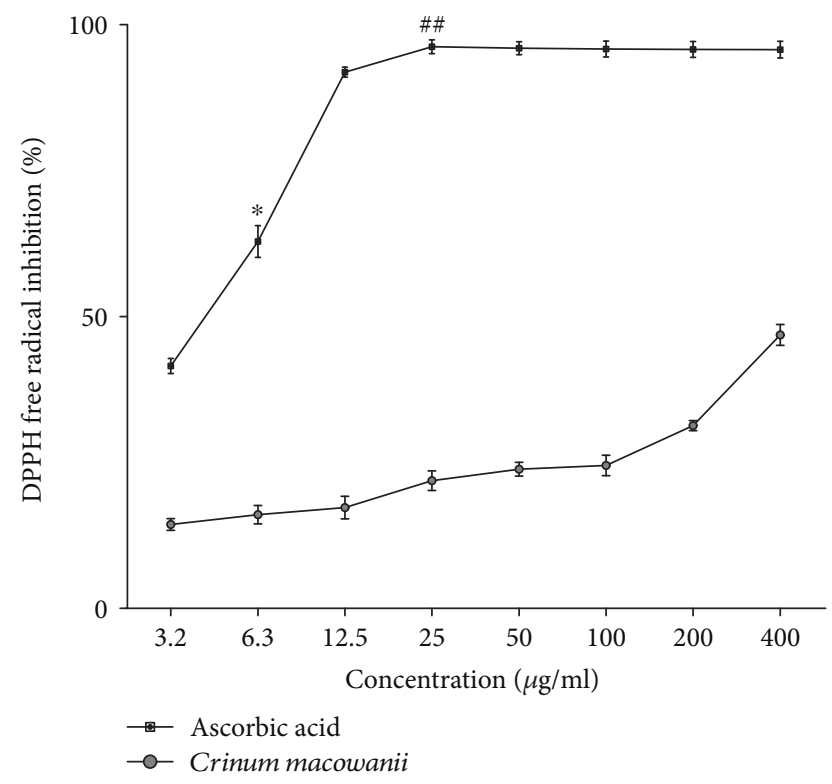

FIGURE 4: DPPH free radical scavenging activity of a crude extract of Crinum macowanii. DPPH radical scavenging activity of Crinum macowanii and ascorbic acid. The data are the representative of three independent experiments. Values are mean \pm SEM. The data were analyzed by two-way ANOVA followed by Bonferroni multiple comparisons test. CM versus $\mathrm{AA},{ }^{*} P<0.0001$; $\mathrm{CM}$ versus AA, ${ }^{\# \# P}<0.0001$.

test is one of the main behavioral tests used to assess memory function, has the ability to differentiate between spatial and nonspatial memory deficits [26], and can also evaluate learning and relearning [27]. A previous study which evaluated the antiamnesic activity of CM suggested that the extract of CM may be used in the treatment of $\mathrm{AD}$ [18]. The study, however, did not utilize the MWM. Moreover, the animal model employed in this current study is known to mimic $\mathrm{AD}$ more closely than the scopolamine mouse model.

$\beta$-amyloid protein $(A \beta P)$ is a peptide resulting from the cleavage of the amyloid precursor protein. This is the basis of the amyloid cascade hypothesis which suggests that the accumulation of $A \beta P$ results in the pathogenesis of $\mathrm{AD}$ $[28,29]$. It has been demonstrated that the polymerization of $A \beta P$ is enhanced by aluminum [30]. Orally administered aluminum was seen to increase the amount of $A \beta P$ in mice [31]. This suggests that the aluminum mouse model is a relevant animal model for $\mathrm{AD}$. The fact that aluminum has a role to play in the amyloid hypothesis and is an abundant metal which can be commonly ingested by humans makes the aluminum mouse model a relevant model for studying the pathogenesis of $\mathrm{AD}$. In this study, the ALCL-treated mice showed the highest EL and the least time spent in target quadrant, which implied memory impairment due to aluminum.

In the MWM test, a decreased EL during 5 days of trials and an increase in time spent in the target quadrant on the $6^{\text {th }}$ day indicated improved memory function. CM at a dosage of $40 \mathrm{mg} / \mathrm{kg}$ showed a significant memory-enhancing effect as compared to the negative control (ALCL) and the vehicle control (water). The CM $40 \mathrm{mg} / \mathrm{kg}$ group was also seen to possess similar memory-enhancing effects as the positive control group-DONZ, which is one of the currently approved medications for treating AD. The DONZ $3 \mathrm{mg} / \mathrm{kg}$ group showed the lowest EL, although not significantly different than the CM $40 \mathrm{mg} / \mathrm{kg}$ group. This suggests that CM at $40 \mathrm{mg} / \mathrm{kg}$ was comparable to DONZ $3 \mathrm{mg} / \mathrm{kg}$ in improving memory function. The significantly shorter EL of the CM $40 \mathrm{mg} / \mathrm{kg}$ treated group as compared to the control group suggests that the C. macowanii extract improved memory function in the MWM test against aluminum chlorideinduced memory impairment. A dose-dependent decrease in EL was seen in all treatment groups of CM with an increase in dose of the extract.

The probe trial on day $6^{\text {th }}$ was performed by removing the platform from the maze. The time spent in the target quadrant by each mouse was noted and a longer amount of time spent in the target quadrant indicated improved memory function. Similar results were observed during the probe trial, wherein the DONZ group spent the longest time in the target quadrant, but no significant difference was seen in time spent in the target quadrant between the DONZ $3 \mathrm{mg} / \mathrm{kg}$ and the CM $40 \mathrm{mg} / \mathrm{kg}$ groups. CM $40 \mathrm{mg} / \mathrm{kg}$ treated mice spent significantly more time in the target quadrant than the ALCL group. The results of the EL and time spent in the target quadrant indicate that $\mathrm{CM}$ extract attenuated aluminuminduced spatial memory impairment.

The novel object recognition test was used to assess short- and long-term memory. The present study evaluated the use of C. macowanii extract for its memory enhancing effect against aluminum chloride-induced memory impairment in mice. 


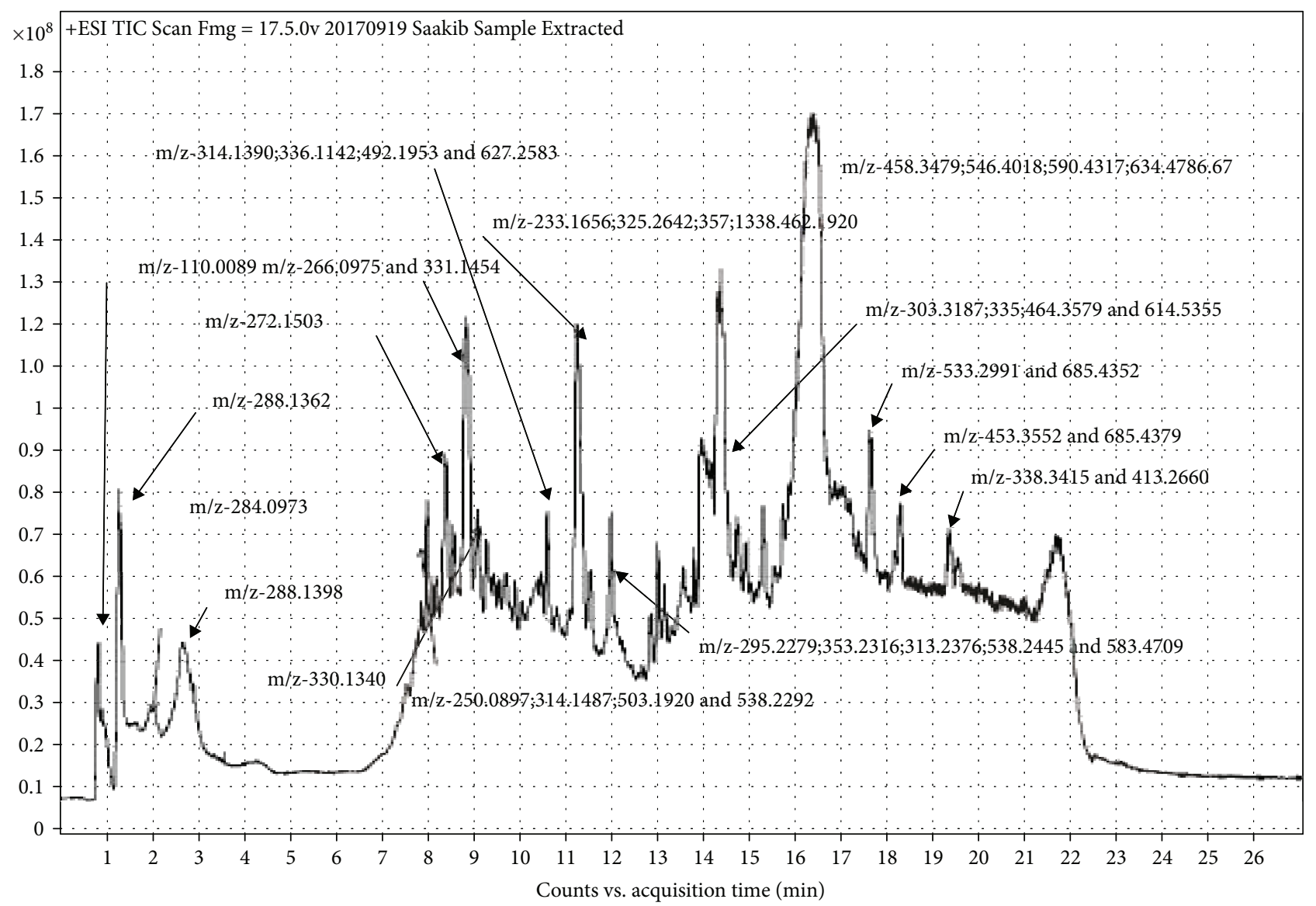

FIGURE 5: The LC-MS fingerprint of a crude hydroethanolic extract of C. macowanii. The LC-MS fingerprint of a crude hydroethanolic extract of $C$. macowanii with prominent peaks.

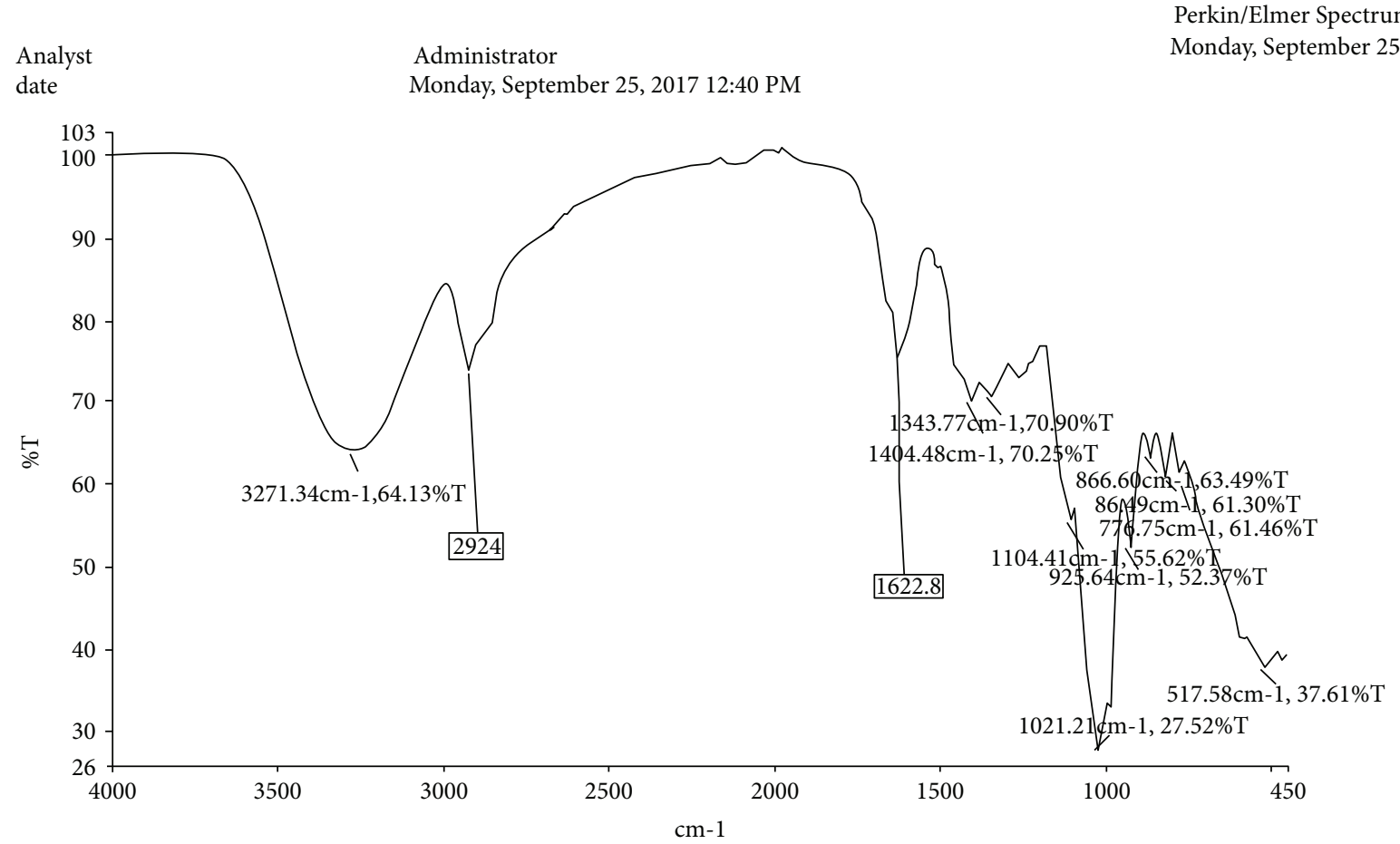

FIGURE 6: FT-IR spectrum of a hydroethanolic extract of Crinum macowanii showing the most prominent peaks. 
Although there was no significant difference in time spent exploring each identical object in the sample phase for short-term memory, significant differences were seen in the test phase.

CM $40 \mathrm{mg} / \mathrm{kg}$ treated mice spent significantly more time exploring the novel object than the familiar object $(P=0.0180)$ for the short-term memory task. This was also confirmed by the percentage of discrimination indices which showed a significant difference as compared to the negative control-ALCL. The increase in DI and exploration time of the novel object in mice treated with C. macowanii at $40 \mathrm{mg} / \mathrm{kg}$ suggested short-term memory enhancing activity. During the long-term memory task for the test phase, no group showed any significant preference for exploring the novel object. Hence, it may be said that none of the doses of C. macowanii can be helpful for improving long-term memory against aluminum-induced memory impairment.

Mugwagwa et al. [18] have demonstrated that CM failed to attenuate memory deficits caused by scopolamine in the short-term memory task of NOR. However, CM at high doses showed long-term memory enhancing activity. In contrast, this study has shown that CM was more effective in improving short-term memory rather than long-term memory in the NOR task. The reason for the difference is unclear but may be due to the different mouse models used in each study.

Various studies have reported the presence of alkaloids in $\mathrm{CM}$, while acetylcholinesterase inhibitory activity has also been reported in some [17]. We know that $\mathrm{AD}$ is a result of neurodegeneration which results in a decrease in cholinergic transmission in the brain [32]. An effective treatment strategy to improve AChE function is to inhibit the enzymeacetylcholinesterase which is responsible for the breakdown of acetylcholine, thereby increasing the amount of acetylcholine. CM is an ideal candidate since we have established that the extract does inhibit AChE. The AChE activity test was performed to assess the enzyme inhibitory activity of CM. A higher enzyme activity indicates an inverse relation with the amount of acetylcholine present in the brain. The AChE assay exhibited a dose-dependent decrease in AChE activity in the CM-treated groups. Isolated samples obtained from the brains of the CM-treated groups showed a significantly lower AChE activity than the ALCL-treated group and the control group. The outcome of this study shows that $\mathrm{CM}$ has an inhibitory effect on the enzyme-AChE. The AChE activity is likely due to the presence of alkaloids such as lycorine [17].

The DPPH free radical scavenging assay was performed to assess the antioxidant activity of the crude extract of CM. Although a dose-dependent increase of free radical scavenging activity was seen with an increased dose of CM, the activity was significantly less than that of ascorbic acid.

Phytochemical screening chemical tests for the hydroethanolic extract of CM showed the presence of glycosides, alkaloids, saponins, steroids, and flavonoids. The presence of flavonoids may play a neuroprotective role in $\mathrm{AD}$.

The pathogenesis of $\mathrm{AD}$ is a complex process resulting from many factors such as ingestion of toxic metals, e.g., aluminum, the decrease in cholinergic transmission, the presence of amyloid protein, and/or neurodegeneration caused by free radicals. These AD-like pathologies may potentially be treated by $\mathrm{CM}$ since this study has shown $\mathrm{CM}$ to possess AChE inhibitory activity and antioxidant activity. Furthermore, CM has shown to attenuate ALCLinduced memory deficits in the MWM and NOR tasks.

\section{Conclusion}

The hydroethanolic crude extract of C. macowanii at a dose of $40 \mathrm{mg} / \mathrm{kg}$ showed short-term memory enhancing activity in the NOR task. The same was not demonstrated in the long-term memory task. C. macowanii at high doses demonstrated a memory-enhancing effect in the Morris water maze test which was seen to be comparable to that of donepezil. Hence, it may be concluded that C. macowanii at high doses ameliorates aluminum chloride-induced memory deficits in mice in the Morris water maze and novel object recognition test and may be of potential benefit in treating $\mathrm{AD}$ and related disorders.

\section{Abbreviations}

AChE: Acetylcholinesterase

AChEi: Acetylcholinesterase inhibitor

A $\beta$ : Amyloid beta

$\mathrm{AD}: \quad$ Alzheimer's disease

ALCL: Aluminum chloride

CM: Crinum macowanii

DONZ: Donepezil

DI: Discrimination index

EL: Escape latency

FT-IR: Fourier-transform infrared spectroscopy

LC-MS: Liquid chromatography-mass spectrometry

MWM: Morris water maze

NOR: Novel object recognition.

\section{Data Availability}

The datasets generated and/or analyzed during the current study are available from the corresponding author on reasonable request.

\section{Conflicts of Interest}

The authors declare that there is no conflict of interests regarding the publication of this paper.

\section{Acknowledgments}

The authors are thankful to the School of Pharmacy, Department of Biochemistry and the Department of Clinical Pharmacology, University of Zimbabwe for the usage of the laboratory facilities. The plant was authenticated by Mr. Chapano from the Botanical Gardens and National Herbarium.

\section{References}

[1] A. Burns and S. Iliffe, "Alzheimer's disease," BMJ, vol. 338, p. b158, 2009. 
[2] J. Sevigny, P. Chiao, T. Bussière et al., "The antibody aducanumab reduces $A \beta$ plaques in Alzheimer's disease," Nature, vol. 537, no. 7618, pp. 50-56, 2016.

[3] J. Hardy and D. Allsop, "Amyloid deposition as the central event in the aetiology of Alzheimer's disease," Trends in Pharmacological Sciences, vol. 12, no. 10, pp. 383-388, 1991.

[4] A. Mudher and S. Lovestone, "Alzheimer's disease-do tauists and baptists finally shake hands?," Trends in Neurosciences, vol. 25, no. 1, pp. 22-26, 2002.

[5] L. Bertram and R. E. Tanzi, "Thirty years of Alzheimer's disease genetics: the implications of systematic meta-analyses," Nature Reviews Neuroscience, vol. 9, no. 10, pp. 768-778, 2008.

[6] J. Folch, D. Petrov, M. Ettcheto et al., "Current research therapeutic strategies for Alzheimer's disease treatment," Neural Plasticity, vol. 2016, Article ID 8501693, 15 pages, 2016.

[7] R. Bartus, R. Dean, B. Beer, and A. Lippa, "The cholinergic hypothesis of geriatric memory dysfunction," Science, vol. 217, no. 4558, pp. 408-414, 1982.

[8] J. L. Cummings and C. Back, "The cholinergic hypothesis of neuropsychiatric symptoms in Alzheimer's disease," The American Journal of Geriatric Psychiatry, vol. 6, no. 2, Supplement 1, pp. S64-S78, 1998.

[9] M. Farlow, "A clinical overview of cholinesterase inhibitors in Alzheimer's disease," International Psychogeriatrics, vol. 14, Supplement 1, pp. 93-126, 2002.

[10] N. Herrmann, S. A. Chau, I. Kircanski, and K. L. Lanctôt, "Current and emerging drug treatment options for Alzheimer's disease," Drugs, vol. 71, no. 15, pp. 2031-2065, 2011.

[11] A. P. Murray, M. B. Faraoni, M. J. Castro, N. P. Alza, and V. Cavallaro, "Natural AChE inhibitors from plants and their contribution to Alzheimer's disease therapy," Current Neuropharmacology, vol. 11, no. 4, pp. 388-413, 2013.

[12] J. Refaat, M. S. Kamel, M. A. Ramadan, and A. A. Ali, "Crinum and an endless source of bioactive principles: a review. Part 1-Crinum alkaloids: lycorine-type alkaloids," International Journal of Pharmaceutical Sciences and Research, vol. 3, no. 7, pp. 1883-1890, 2012.

[13] J. Refaat, M. S. Kamel, M. A. Ramadan, and A. A. Ali, “Crinum and an endless source of bioactive principles: a review, part II. Crinum alkaloids: crinine-type alkaloids," International Journal of Pharmaceutical Sciences and Research, vol. 3, no. 9, p. 3091, 2012.

[14] J. Refaat, M. S. Kamel, M. A. Ramadan, and A. A. Ali, "Crinum, III, an endless source of bioactive principles: a review. Part 1crinum alkaloids: belladine-, galanthamine-, lycorenine-, tazettine-type alkaloids and other minor types," International Journal of Pharmaceutical Sciences and Research, vol. 3, no. 10, p. 3630, 2012.

[15] A. Maroyi, "A review of ethnoboatany, therapeutic value, phytochemistry and pharmacology of Crinum macowanii Baker: a highly traded bulbous plant in Southern Africa," Journal of Ethnopharmacology, vol. 194, pp. 595-608, 2016.

[16] E. E. Elgorashi, S. E. Drewes, and J. Van Staden, “Organ-toorgan and seasonal variation in alkaloids from Crinum macowanii," Fitoterapia, vol. 73, no. 6, pp. 490-495, 2002.

[17] E. E. Elgorashi, G. I. Stafford, and J. van Staden, “Acetylcholinesterase enzyme inhibitory effects of Amaryllidaceae alkaloids," Planta Medica, vol. 70, no. 3, pp. 260-262, 2004.

[18] A. T. Mugwagwa, L. L. Gadaga, W. Pote, and D. Tagwireyi, "Antiamnesic effects of a hydroethanolic extract of Crinum macowanii on scopolamine-induced memory impairment in mice," Journal of Neurodegenerative Diseases, vol. 2015, Article ID 242505, 9 pages, 2015.

[19] G. M. Berlyne, J. Ben Ari, E. Knopf, R. Yagil, G. Weinberger, and G. M. Danovitch, "Aluminium toxicity in rats," Lancet, vol. 299, no. 7750, pp. 564-568, 1972.

[20] J. R. McDermott, A. I. Smith, K. Iqbal, and H. M. Wisniewski, "Brain aluminum in aging and Alzheimer disease," Neurology, vol. 29, no. 6, pp. 809-814, 1979.

[21] F. Ashall and A. M. Goate, "Role of the $\beta$-amyloid precursor protein in Alzheimer's disease," Trends in Biochemical Sciences, vol. 19, no. 1, pp. 42-46, 1994.

[22] Z. I. Linardaki, M. G. Orkoula, A. G. Kokkosis, F. N. Lamari, and M. Margarity, "Investigation of the neuroprotective action of saffron (Crocus sativus L.) in aluminum-exposed adult mice through behavioral and neurobiochemical assessment," Food and Chemical Toxicology, vol. 52, pp. 163-170, 2013.

[23] K. Bromley-Brits, Y. Deng, and W. Song, "Morris water maze test for learning and memory deficits in Alzheimer's disease model mice," Journal of Visualized Experiments, no. 53, 2011.

[24] S. K. Doreddula, S. R. Bonam, D. P. Gaddam, B. S. R. Desu, N. Ramarao, and V. Pandy, "Phytochemical analysis, antioxidant, antistress, and nootropic activities of aqueous and methanolic seed extracts of ladies finger (Abelmoschus esculentus L.) in mice," The Scientific World Journal, vol. 2014, Article ID 519848, 14 pages, 2014.

[25] M. Yadav, S. Chatterji, S. K. Gupta, and G. Watal, "Preliminary phytochemical screening of six medicinal plants used in traditional medicine," International Journal of Pharmacy and Pharmaceutical Sciences, vol. 6, no. 5, pp. 539-542, 2014.

[26] R. D’Hooge and P. P. De Deyn, “Applications of the Morris water maze in the study of learning and memory," Brain Research Reviews, vol. 36, no. 1, pp. 60-90, 2001.

[27] A. V. Terry Jr and J. J. Buccafusco, "Spatial navigation (water maze) tasks," in Methods of Behavior Analysis in Neuroscience, pp. 169-182, CRC Press, 2009.

[28] J. Hardy and D. J. Selkoe, “The amyloid hypothesis of Alzheimer's disease: progress and problems on the road to therapeutics," Science, vol. 297, no. 5580, pp. 353-356, 2002.

[29] O. Wirths, G. Multhaup, and T. A. Bayer, "A modified $\beta$-amyloid hypothesis: intraneuronal accumulation of the $\beta$-amyloid peptide - the first step of a fatal cascade," Journal of Neurochemistry, vol. 91, no. 3, pp. 513-520, 2004.

[30] M. Kawahara and M. Kato-Negishi, "Link between aluminum and the pathogenesis of Alzheimer's disease: the integration of the aluminum and amyloid cascade hypotheses," International Journal of Alzheimer's Disease, vol. 2011, Article ID 276393, 17 pages, 2011.

[31] D. Praticò, K. uryu, S. Sung, S. Tang, J. Q. Trojanowski, and V. M. Y. Lee, "Aluminum modulates brain amyloidosis through oxidative stress in APP transgenic mice," The FASEB Journal, vol. 16, no. 9, pp. 1138-1140, 2002.

[32] D. Schuster, M. Spetea, M. Music et al., "Morphinans and isoquinolines: acetylcholinesterase inhibition, pharmacophore modeling, and interaction with opioid receptors," Bioorganic \& Medicinal Chemistry, vol. 18, no. 14, pp. 5071-5080, 2010. 


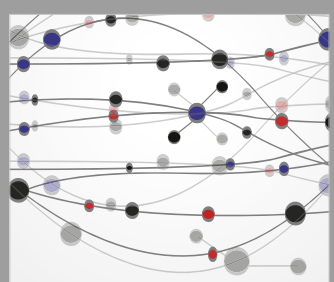

The Scientific World Journal
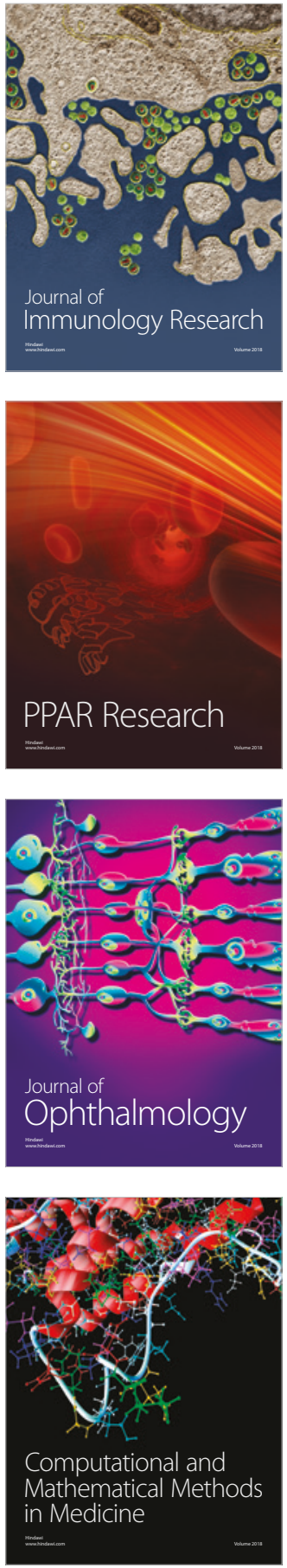

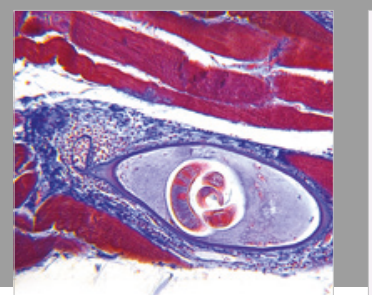

Gastroenterology Research and Practice

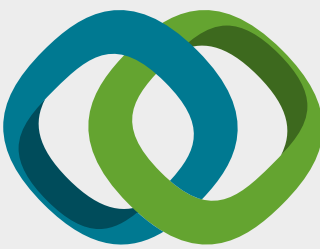

\section{Hindawi}

Submit your manuscripts at

www.hindawi.com
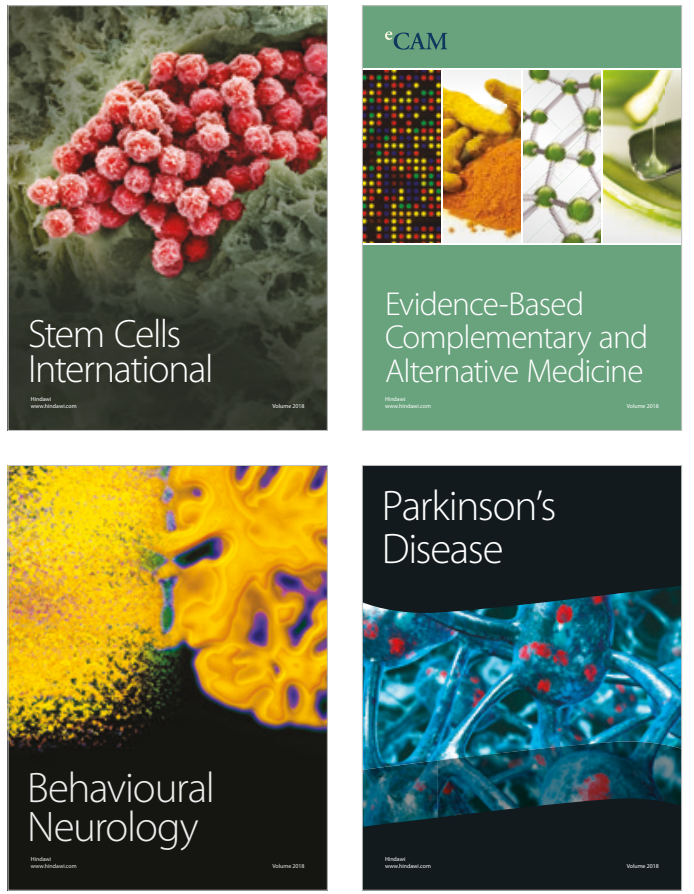

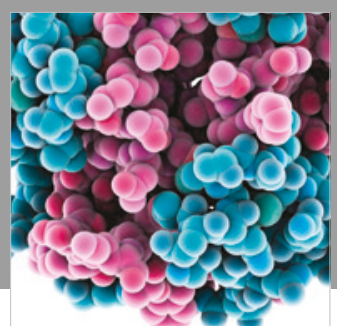

ournal of

Diabetes Research

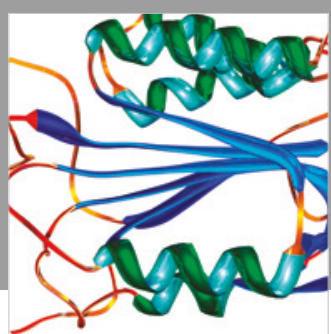

Disease Markers
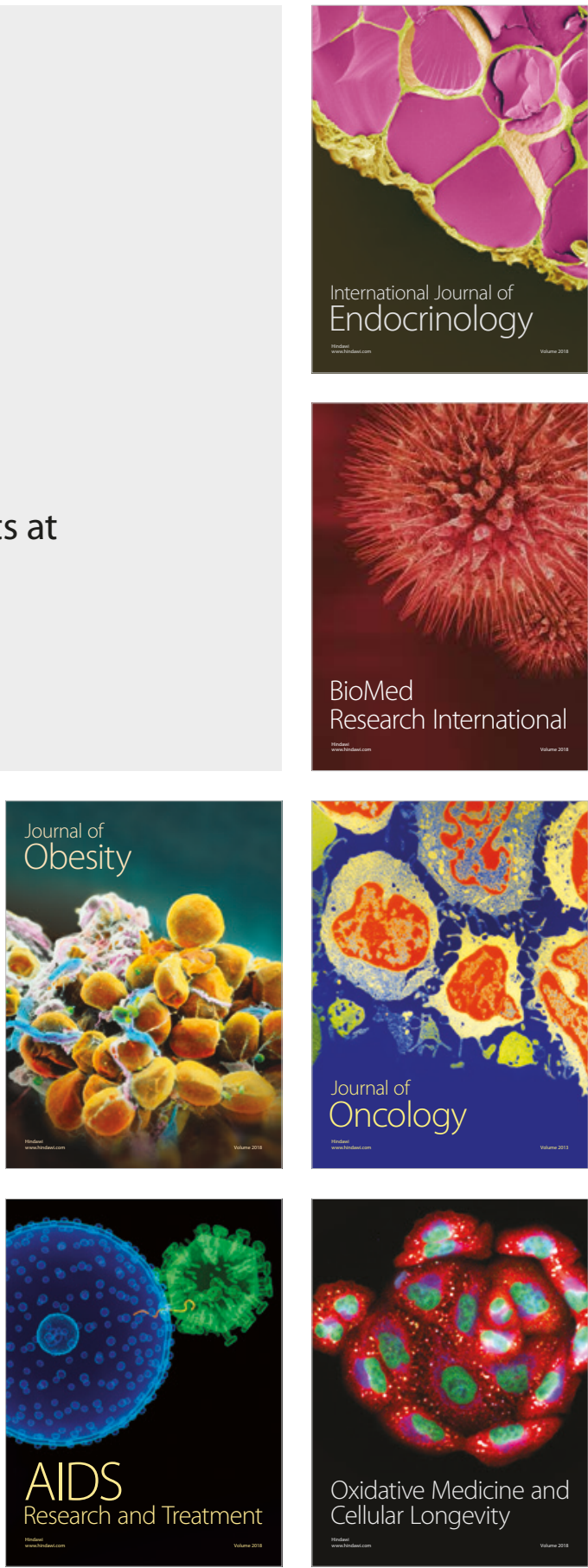